\title{
RyR1 Deficiency in Congenital Myopathies Disrupts Excitation-Contraction Coupling
}

Haiyan Zhou ${ }^{1}$, Ori Rokach ${ }^{2}$, Lucy Feng ${ }^{1}$, Iulia Munteanu ${ }^{1}$, Kamel Mamchaoui ${ }^{3}$, Jo M. Wilmshurst ${ }^{4}$, Caroline Sewry ${ }^{1}$, Adnan Y. Manzur ${ }^{1}$, Komala Pillay $^{5}$, Vincent Mouly ${ }^{2}$, Michael Duchen $^{6}$, Heinz Jungbluth ${ }^{7,8,9}$, Susan Treves ${ }^{2,10^{*}}$ and Francesco Muntoni ${ }^{*}$

1. Dubowitz Neuromuscular Centre, Institute of Child Health, University College London WC1N 1EH, UK.

2. Department of Anaesthesia and Biomedicine, Basel University and University Hospital Basel, 4031 Basel, Switzerland

3. UM76 Université Pierre et Marie Curie, UMRS974 INSERM, UMR 7215 CNRS, Institut de Myologie AIM, Groupe hospitalier Pitié-Salpétrière, 47 bd de I'Hôpital, 75013 Paris, France

4. Department of Paediatric Neurology, School of Child and Adolescent Health, University of Cape Town, Red Cross Children's Hospital, Cape Town, South Africa

5. Department of Paediatric Pathology, School of Child and Adolescent Health, University of Cape Town, Red Cross Children's Hospital, Cape Town, South Africa

6. Cell and Developmental Biology, University College London, London WC1E 6BT, UK

7. Department of Paediatric Neurology, Evelina Children's Hospital, London SE1 7EH, UK

8. Clinical Neuroscience Division, IoP, King's College, London, UK

9. Randall Division of Cell and Molecular Biophysics, Muscle Signalling Group, King's College London, UK

10. Department of Life Sciences, University of Ferrara, Ferrara, Italy 
*To whom correspondence should be addressed. Emails: f.muntoni@ucl.ac.uk (Tel: 00442079052136; Fax: 0044-2079052832) and susan.treves@unibas.ch (Tel:0041612652373; Fax:0041612653702)

\section{Key Words}

Skeletal muscle ryanodine receptor gene; dihydropyridine receptor; inositol-1,4,5triphosphate receptor; congenital myopathies; excitation-contraction coupling 


\section{ABSTRACT}

In skeletal muscle, excitation-contraction coupling is the process whereby the voltage-gated dihydropyridine receptor (DHPR) located on the transverse tubules activates calcium release from the sarcoplasmic reticulum by activating ryanodine receptor (RyR1) $\mathrm{Ca}^{2+}$ channels located on the terminal cisternae. This subcellular membrane specialization is necessary for proper intracellular signalling and any alterations in its architecture may lead to neuromuscular disorders. In this study we present evidence that patients with recessive $R Y R I$ related congenital myopathies due to primary RyR1 deficiency also exhibit down-regulation of the alfa 1 subunit of the DHPR and show disruption of the spatial organization of the excitation-contraction coupling machinery. We created a cellular RyR1 knock-down model using immortalized human myoblasts transfected with RyR1 siRNA and confirm that knocking down RyR1 concomitantly down-regulates not only the DHPR but also the expression of other proteins involved in excitation-contraction coupling. Unexpectedly, this was paralleled by the up-regulation of inositol-1,4,5-triphosphate receptors; functionally however, up-regulation of the latter $\mathrm{Ca}^{2+}$ channels did not compensate for the lack of RyR1mediated $\mathrm{Ca}^{2+}$ release. These results indicate that in some patients, RyR1 deficiency concomitantly alters the expression pattern of several proteins involved in calcium homeostasis and that this may influence the manifestation of these diseases. 


\section{Introduction}

The precise regulation of intracellular calcium homeostasis is critical for normal skeletal muscle development and function. Excitation-contraction (E-C) coupling requires the correct assembly, distribution and interaction of a number of proteins found in the sarcoplasmic reticulum (SR), the organelle of striated muscle dedicated to calcium homeostasis. Two key elements involved in calcium release are the voltage-gated dihydropyridine receptor (DHPR, MIM\# 114208), located on the transverse tubules, and the ryanodine receptor (RyR1, MIM\# 180901), the principal calcium release channel of skeletal muscle situated in the terminal cisternae of the SR (Nakai et al., 1996). The predicted structure of the RyR1 suggests that the calcium release pore is located in the C-terminal domain of the protein, whereas the Nterminal domain constitutes the foot structure that interacts with DHPR (Ramachandran et al., 2009; VanPetegem, 2012; Dulhunty and Pouliquin, 2003). The direct physical interaction between DHPR and RyR1 is essential for skeletal muscle E-C coupling and any alterations in the subcellular distribution of proteins or membranes involved E-C coupling can lead to impaired muscle function (Pan et al., 2002; Oddoux et al., 2009).

Disturbance of calcium homeostasis due to defects in RyR1 is the underlying feature of the malignant hyperthermia susceptibility (MHS, MIM\# 145600) trait, a pharmacogenetic reaction to volatile anaesthetics and muscle relaxants, and a wide range of congenital myopathy phenotypes, including dominantly inherited Central Core Disease (CCD, MIM\# $117000)$ and recessively inherited Multi-minicore Disease (MmD, MIM\# 255320) with or without opthalmoplegia (Jungbluth et al., 2002; Jungbluth et al., 2005; Quane et al., 1993; Zhou et al., 2006; Zhou et al., 2007), subgroups of Centronuclear Myopathy (CNM), Congenital Fibre Type Disproportion (CFTD) and the King-Denborough Syndrome (KDS) (Clarke et al., 2010; Dowling et al., 2011; Wilmshurst et al., 2010; Jungbluth et al., 2007). Whilst dominantly inherited $R Y R l$-related congenital myopathies have been extensively 
studied and are usually attributed to RyR1 channels that are either "leaky" or show impaired calcium conductance (Treves et al., 2008; Dirksen and Avila, 2002), the pathogenesis of recessively inherited $R Y R I$-related myopathies is not well understood, though a decrease in RyR1 protein content has been reported in muscle biopsies from some patients (Zhou et al., 2007; Wilmhurst et al., 2010). Besides mutations in the RYRl, substitutions in other genes linked to neuromuscular disorders, encoding proteins involved in E-C coupling have so far been reported only for $C A C N A 1$, the gene encoding the alfa 1 subunit of the DHPR $\left(\mathrm{Ca}_{\mathrm{v}} 1.1\right)$ in patients with malignant hyperthermia (Pirone et al., 2010; Toppin et al., 2010; Monnier et al., 1997). We recently reported that a patient with periodic paralysis who harboured recessively inherited $R Y R 1$-mutations (Zhou et al., 2010) with no CACNA1S mutation, had a marked reduction of RyR1 protein and a disruption of $\mathrm{RyR} 1 / \mathrm{Ca}_{\mathrm{v}} 1.1$ co-localization, indicating potential secondary effects of certain RYR1 mutations on key proteins of the E-C coupling machinery.

In the present investigation we extended these findings and report abnormal expression and distribution of $\mathrm{Ca}_{\mathrm{v}} 1.1$ in muscle biopsies from a number of patients with recessive RYR 1 mutations with reduced RyR1 content. Mimicking RyR1 depletion in human myotubes using a $R Y R 1$ siRNA knock down approach caused a decrease in $\mathrm{Ca}_{\mathrm{v}} 1.1$ with a concomitant up-regulation of inositol-1,4,5-trisphosphate receptors (IP3R, MIM\# 147265). These results provide new insights into the pathogenesis of recessive $R Y R 1$-related myopathies with primary RyR1 deficiency. 


\section{Materials and Methods}

\section{Muscle Biopsies}

Studies on muscle biopsies from patients were approved by the author's Institutional Ethical Committee and conducted under the Declaration of Helsinki. Patients were encoded to protect their confidentiality, and written informed consent obtained. Routine histopathological studies were performed according to standard procedures. All patients presented in this study have a clear clinical and histological diagnosis of a congenital myopathy, and were molecularly diagnosed as having RYRl mutations. Control muscle biopsies were from donors with no neuromuscular diseases. RNA samples were studied in 19 patients and 9 controls; immunohistochemical studies were performed in 4 patients and 3 controls; Western blot studies were performed in 2 patients and 3 controls.

\section{Molecular Genetics}

The genetic information of all patients was taken from the genetic reports. The RYRI nucleotide numbering is based on transcript variant NM_00540.2, where the nucleotide numbering reflects cDNA numbering with +1 corresponding to the A of the ATG translation initiation codon in the reference sequence, according to journal guidelines (www.hgvs.org/mutnomen). The initiation codon is codon 1. The variants reported have been submitted to the Leiden RYR1 locus specific database (http://www.lovd.nl/RYR1).

\section{Immortalization and Culture of Skeletal Muscle Cell Line}

Human satellite cells were derived from the skeletal muscle biopsy of a 19-year-old female donor with no neuromuscular disorder. Skeletal muscle cell line immortalization was performed as previously described (Zhu et al., 2007; Mamchaoui et al., 2011). Briefly, cultured cells were double transfected by recombinant retroviruses containing the telomerase (hTERT) cDNA and Cdk4 cDNA, followed by clonal selection of myogenic lines. 
Immortalized myoblasts were maintained in skeletal muscle cell growth medium (PromoCell) in low oxygen atmosphere $\left(5 \% \mathrm{O}_{2}\right.$ and $\left.5 \% \mathrm{CO}_{2}\right)$ at $37^{\circ} \mathrm{C}$.

\section{Immunofluorescence}

All cryosections from muscle biopsies were cut at a thickness of $8 \mu \mathrm{m}$ for immunohistochemistry. Sections were incubated with primary antibodies at room temperature for one hour, washed in 0.1M phosphate buffered saline pH 7.2 (PBS) and incubated with secondary antibody conjugated to Alexa 488 and biotinylated secondary antibody for one hour at room temperature, followed by thorough rinsing in PBS. After washing, muscle sections were incubated with streptavidin conjugated to Alexa 594 for 15 minutes at room temperature then washed and mounted using Hydromount mounting medium (National Diagnostics). Images were digitally captured using Metamorph software. For immunofluorescence on myotubes, glass coverslip grown cells were fixed for 30 minutes in 3.7\% paraformaldehyde in PBS; cells were rinsed with PBS and permeabilized with $1 \%$ Triton X-100 in PBS for 30 minutes. After incubation with blocking buffer (1\% blocking buffer, Roche, in PBS) for 60 min at room temperature, slides were processed as described above. The primary antibodies used for immunohistochemistry were mouse anti-RyR1 monoclonal antibody (1:500, Abcam), goat anti- $\mathrm{Ca}_{\mathrm{v}} 1.1$ polyclonal antibody (1:200, Santa Cruz) and rabbit anti-ß-tubulin (1:20, Santa Cruz).

\section{cDNA Synthesis and Quantitative Real-time PCR}

Total RNA was extracted from muscle biopsies using the RNeasy kit (Qiagen); 500 ng of each RNA sample was used for first-strand cDNA synthesis with Superscript III reverse transcription kit (Invitrogen). Quantitative real-time PCR products of RYR1, CACNA1S and DES were amplified with the TaqMan universal PCR Master Mix (Applied Biosystems). Samples were incubated in a $25 \mu 1$ reaction mix according to manufacturer's instructions. Quantitative real-time PCR was performed using Applied Biosystem fast 7500 Real Time 
PCR System using the recommended program: activation at $50^{\circ} \mathrm{C}$ for 2 min and $95^{\circ} \mathrm{C}$ for 10 min, 40 cycles of $95^{\circ} \mathrm{C}$ for $15 \mathrm{sec}$ and $60^{\circ} \mathrm{C}$ for $1 \mathrm{~min}$. Quantification was based on the comparative $\Delta \Delta \mathrm{Ct}$ method. One of the samples treated with negative control siRNA was used to calibrate the data and to analyse results. For ITPR 1, ITPR2 and ITPR3 quantitative realtime PCR samples were amplified with MESA Blue qPCR kit (Eurogentec). Gene specific qPCR primers, including ITPR1, ITPR2, ITPR3, GAPDH and DES, were commercially available from Qiagen. Samples were incubated in a $25 \mu 1$ reaction mix according to manufacturer's instructions. Quantitative real-time PCR was performed using Applied Biosystem fast 7500 Real Time PCR System using the recommended program: activation at $95^{\circ} \mathrm{C}$ for $5 \mathrm{~min}, 40$ cycles of $95^{\circ} \mathrm{C}$ for $3 \mathrm{sec}$ and $60^{\circ} \mathrm{C}$ for $1 \mathrm{~min}$. Quantification was based on concurrent standard curves produced from serial dilutions of control cDNA from untreated cultured myotubes. DES and GAPDH were used as internal reference genes. The expression of ITPRs in cultured myotubes or muscle biopsies were normalized by DES or GAPDH, and calibrated by taking the ratio of one of the control samples as 1.0. Total RNA was extracted from human myotubes using Trizol (Invitrogen) and cDNA synthesized with the High Capacity cDNA synthesis kit from Applied Biosystem and the following primers: MYH 1Myosin heavy chain: Forward : 5' GGG AGA CCT AAA ATT GGC TCA A 3' Reverse: 5' TTG CAG ACC GCT CAT TTC AAA 3' TNNT1 - Troponin T1 : Forward: 5' TGA TCC CGC CAA AGA TCC C 3' Reverse: 5' TCT TCC GCT GCT CGA AAT GTA 3' DAG1 Dystroglycan 1 : Forward: 5' AGC AAA GGA TTG ACC TCC TGC 3' Reverse: 5' CCA CCG GCA CTA ATT TCA TGT T 3' Desmin : Forward : 5' AAC CAG GAG TTT CTG ACC ACG 3' Reverse: 5' TTG AGC CGG TTC ACT TCG G 3' GAPDH: Forward : 5' CTG GGC TAC ACT GAG CAC C 3' Reverse: 5'AAG TGG TCG TTG AGG GCA ATG 3'. As well as the ITPR primers described above. Transcript levels were normalized to GAPDH expression levels. 


\section{Western Blotting}

Total protein was extracted from cells lysates or frozen skeletal muscle sections in sampling buffer consisting of $75 \mathrm{mM}$ Tris-HCl, 1\% SDS and cocktail of protease inhibitor (Roche). Protein concentration was quantified by the BCA protein assay kit (Pierce). Thirty micrograms of proteins were loaded and separated using NuPAGE Pre-cast gels (3-8\% Trisacetate, Invitrogen) and then transferred electrophoretically to nitrocellulose membrane (GE Healthcare). The membrane was blocked with 5\% goat serum (Sigma) in phosphate buffered saline buffer with $0.5 \%$ Tween-20 (PBS-T) and then probed with primary antibodies at room temperature for 1 hour or $4^{\circ} \mathrm{C}$ overnight. After washing in PBS-T, membranes were incubated with HRP-anti-mouse or HRP-anti-rabbit IgG (the Jackson Laboratory, 1:50,000) for one hour at room temperature. Immunoreactivity was visualized using enhanced chemiluminescence detection kit (GE Healthcare). Semi-quantification of the bands was performed by densitometric analysis and data was processed using the Image J software.

The primary antibodies used in this study include mouse monoclonal anti-RyR1 (Abcam, 1:2,500), rabbit anti- $\mathrm{Ca}_{\mathrm{v}} 1.1$ (Santa Cruz, 1:1,000), mouse monoclonal -anti-desmin (DAKO, 1:2,000), mouse monoclonal anti- IP3R III (BD, 1:1,000), mouse monoclonal anti-SERCA2 antibody (Abcam, 1:1,000), mouse monoclonal anti $\alpha$-actinin 2 (Sigma, 1:20,000) and mouse monoclonal anti- $\beta$-tubulin (Sigma, 1:4,000).

\section{RYR1 Knock-down by siRNA}

Immortalized myoblasts obtained as described above (Immortalization and culture human skeletal muscle cell line) were seeded on $30 \mathrm{~mm}$ diameter plates at a density of $5 \sim 8 \times 10^{5}$ cells per well in order to be confluent by the next day. RYRl siRNA (Santa Cruz Biotechnology) was transfected using lipofectamine 2000 in OptiMEM medium following the manufacturer's recommendations (Invitrogen). A series of concentrations $[10 \mathrm{nM}, 30 \mathrm{nM}$ and $50 \mathrm{nM}]$ of siRNA were tested and cells treated with the same concentrations of negative 
siRNA were used as control. The transfection medium was changed to differentiation medium (PromoCell) 6 hours post transfection and changed thereafter every 2 days; cells visibly started to fuse 4-5 days after transfection/differentiation, and myotubes were collected at day 7 .

\section{Intracellular Calcium Measurements}

Myotubes, mock transfected or transfected with 50nM siRNA, were either untreated or treated with $1 \mu \mathrm{M}$ Xestsospongin $\mathrm{C}$ (Sigma chemicals) for 40 minutes during fura-2 (final concentration was $5 \mu \mathrm{M}$ ) loading. Cells were rinsed one time with Krebs-Ringer and then coverslips were mounted onto a $37^{\circ} \mathrm{C}$ thermostated chamber which was continuously perfused with Krebs Ringer medium; individual cells were stimulated with the indicated agonists $(60 \mathrm{mM} \mathrm{KCl}, 600 \mu \mathrm{M}$ 4-chloro-m-cresol, $100 \mu \mathrm{M}$ ATP) made up in Krebs Ringer containing no added $\mathrm{Ca}^{2+}$ plus $100 \mu \mathrm{M} \mathrm{La}^{3+}$ in order to monitor changes in the cytoplasmic calcium concentration due to release from intracellular stores, by means of a 12 -way $100 \mathrm{~mm}$ diameter quartz micromanifold computer-controlled microperfuser (ALA Scientific Instruments), as previously described (Ducreux et al., 2004). On-line measurements were recorded using a fluorescent Axiovert S100 TV inverted microscope (Carl Zeiss GmbH, Jena, Germany) equipped with a $20 \times$ water-immersion FLUAR objective $(0.17 \mathrm{NA})$, filters (BP 340/380, FT 425, BP 500/530) and attached to a Cascade 125+ CCD camera. Changes in the free cytosolic calcium concentration were analysed using MetaMorph (molecular devices) imaging system and the average pixel value for each cell was measured as previously described (Ducreux et al., 2004; Treves et al., 2010).

\section{Statistical Analysis}

Statistical analysis was performed using the Student's $t$ test for comparison of two samples or the ANOVA test for comparison of multiple data, followed by the Bonferroni's post hoc test. GraphPad Prism 5 and Origin softwares were used for statistical analysis and graph design. 


\section{Results}

RyR1 and DHPR Expression and Distribution in Skeletal Muscle Biopsies from Patients Carrying RYR1 Mutations

Fig. 1 shows immunohistochemical staining on skeletal muscle biopsies from three patients carrying recessive $R Y R I$ mutations, one patient carrying a dominant $R Y R I$ mutation and one control individual. A summary of the clinical and histopathological features and genetic details of the patients is given in Supplementary Table S1. Patient 1 carried the heterozygous mutations p.R109W+p.M485V in one allele and the missense plus nonsense mutations p.D708N+p.R2241X in the other allele; patient 2 carried the heterozygous p.E879K mutation in one allele and the splice site mutation c. $3381+1 \mathrm{G}>\mathrm{A}$ in the other allele. Patient 3 carried the dominant RYRI mutation p.G4638D and patient 4 carried the homozygous missense mutation p.R3772Q. No additional mutations were found after screening the entire RYRl coding region of each patient. Biopsies from patients 3 and 4, where histopathology showed typical central or eccentric cores on NADH staining, showed the same patterns of distribution of DHPR and RyR1 in a rim around the core area (Fig. 1). On the other hand, a segregated distribution of RyR1 and DHPR was observed in muscle sections from patients 1 and 2, in whom histopathology showed the characteristic multi-mini cores on NADH staining, there was distinct aggregation of the DHPR in some of the muscle fibres in associated with reduction of RyR1 staining.

\section{RYR1 But Not CACNA1S Transcript Is Reduced in Skeletal Muscle from Patients Carrying Recessive RYR1 Mutations}

To investigate changes in RYRI expression at the transcriptional level, we performed quantitative real-time PCR of RYRl in patient's muscle biopsies, using DES as the skeletal muscle specific reference gene. RNA samples extracted from muscle biopsies of 19 patients 
with confirmed RYR1 mutations were collected for this study. Patients were arranged into three groups according to the types of mutations. RYRl-AD group consisted of 6 patients carrying dominant RYRl mutations; RYRl-R1 group included 4 patients with recessive homozygous or compound heterozygous missense mutations; and RYR1-R2 group included 9 patients carrying heterozygous recessive mutations in which one allele contained a missense mutation, and the other a loss of function mutation. We also included biopsies from 9 normal control individuals in the control group. The relative expression of $R Y R l$ was $0.89 \pm 0.07$ in the control group, $0.83 \pm 0.10$ in the $R Y R l$-AD group, $0.61 \pm 0.07$ in the $R Y R 1-\mathrm{R} 1$ group and $0.57 \pm 0.06$ in the $R Y R 1-\mathrm{R} 2$ group (Fig. $2 \mathrm{~A}$ ). Significant reduction of $R Y R 1 \mathrm{mRNA}$ transcripts was observed in $R Y R 1-\mathrm{R} 1$ and $R Y R 1-\mathrm{R} 2$ groups, where patients were affected by recessive mutations on both alleles, compared to control group $(\mathrm{P}=0.0035$ between $R Y R 1-\mathrm{R} 2$ and control; $\mathrm{P}=0.044$ between $R Y R l-\mathrm{R} 1$ and control). No difference was observed in patients carrying dominant RYRl mutations (RYRl-AD) compared with control group. CACNA1S mRNA was also measured by quantitative real-time but no significant difference was observed in its transcription level in muscle biopsies between mutation groups and controls (Fig. 2B).

We further investigated the effects of RyR1 depletion by performing RyR1 knockdown experiments on an immortalized human muscle cell line, using RYRl siRNA. Seven days after transfection and differentiation, once visible multinucleated myotubes appeared, RYRl mRNA was quantified by real-time PCR. As shown in Fig. 3A the RYRl transcript was reduced in a siRNA concentration- dependent manner. The relative expression of $R Y R 1$ mRNA was: $0.47 \pm 0.09$ for the $10 \mathrm{nM}$ siRYR 1 group; $0.31 \pm 0.03$ for the $30 \mathrm{nM}$ siRYR1 group and $0.23 \pm 0.03$ for the $50 \mathrm{nM}$ siRYR1 group compared to the control group (1.0 \pm 0.0$)$. In the same samples the relative expression of CACNA1S (Fig. 3B) and DES (Fig. 3C) were not significantly changed. 
Down-regulation of RyR1 by siRNA did not affect myotube differentiation; indeed mean myotube diameter as well as the relative expression of differentiation-related markers such as dystroglycan 1 (DAG), myosin heavy chain 1 (MHC1), troponin T1 (TNNT1) and desmin (DES) (Galbiati et al., 1999; Trendelenburg et al., 2009) were similar in control and RYR1 siRNA transfected myotubes (Fig. 4).

\section{RyR1 Deficiency Affects Ca 1.1 Content}

We next assessed if the decrease in mRNA in siRNA transefcted immortalized cells was paralleled by a decrease in protein content. Fig. 5A shows a representative western blot performed seven days after treatment and Fig. 5B shows the mean $( \pm$ SEM) protein content in control versus siRNA treated myotubes. As shown desmin and tubulin content were not affected by RYR1 siRNA but there was a $>50 \%$ decrease in RyR1, Ca 1.1 , SERCA2 and $\alpha$ actinin content as assessed by western blotting in myotubes transfected with $50 \mathrm{nM} \mathrm{RYR1}$ siRNA. Unexpectedly, the relative content of IP3RIII, the other intracellular $\mathrm{Ca}^{2+}$ release channel of ER membranes was increased by approximately two-fold.

The protein content of $\mathrm{Ca}_{\mathrm{v}} 1.1$, SERCA2, $\alpha$-actinin2 and IP3RIII were also assessed in the muscle biopsies from patients with RyR1 deficiency due to recessive mutations. Western blotting was performed on protein extracted from the muscle biopsies of two patients and three normal controls. The immunohistochemical staining of RyR1 and DHPR of patient 2 was shown in Fig. 1; the double staining of RyR1 and DHPR in patient 5 has been previously reported (Zhou et al., 2010), with similar distribution pattern as shown in Fig. 1.

Representative blots from patients and controls are shown in Fig. 5C. There was a significant reduction of both RyR1 and DHPR proteins in the samples from the patients compared to controls (N=3) (Fig. 5D). Significant up-regulation of IP3R III (approximately two-fold) was also observed in patients' muscle biopsies compared to the controls (Fig. 5D). 
However, no changes in SERCA2 and $\alpha$-actinin 2 protein was observed in the patients' muscle biopsies samples.

\section{All Three Types of ITPRs Transcripts Are Up-regulated in RYR1 Knockdown Myotubes and in Skeletal Muscles from Patients with Primary RyR1 Deficiency}

The transcripts of all three isoforms of Inositol-1,4,5- Triphosphate Receptor (IP3R) genes (ITPR 1, ITPR2 and ITPR3) were quantified by real-time RT-PCR in myotubes treated by $R Y R I$ siRNA. Significant up-regulation of all three isoforms of ITPRs was observed in the RYRl knocked down group compared to the control group (Fig. 6A). We then analysed ITPRs transcripts in skeletal muscle from controls $(\mathrm{N}=7)$, from patients with dominant $R Y R 1$ mutations $(\mathrm{N}=5)$ and from patients with heterozygous recessive $R Y R 1$ mutations and RyR1 protein deficiency $(\mathrm{N}=6)$. To ensure that the observed alterations were not due to heterogeneous tissue composition of the biopsies due to variable degrees of fibrosis or connective tissue accumulation, we used both the ubiquitous housekeeping gene GAPDH and muscle specific DES gene as internal reference genes. Irrespective of whether the analysis was made using GAPDH (Fig. 6B) or DES (Fig. 6C), patients with recessive RYR1 mutations showed significant up-regulations of all three IP3R transcripts, compared to the control group. No significant differences in ITPR 1, ITPR 2 and ITP3R expression were observed between the group of patients harbouring dominant RYRl mutations and the control group, except for a patient carrying the dominant mutation p.R4861C, who showed unusually high levels of ITPRs expression. Interestingly, though this mutation was identified as de novo and was not found in either parent, the case was initially considered a recessive core myopathy because of the severe clinical features of the patient and the abnormality observed in parent's muscle biopsy (Manzur et al., 1998). Unfortunately the muscle biopsy failed western blotting RyR1 protein quantification due to sampling problems. In order to rule out the presence of other 
allelic mutations, we performed genomic analysis of the entire coding region and exon/intron boundaries of the $R Y R 1$ gene; no other pathogenic variants were identified in this patient suggesting that in this patient the p.R4861C mutation is responsible for the pathological phenotype.

Taken together these results confirm that RyR1 deficiency induced in vitro as well as RyR1 protein deficiency occurring in vivo due to recessive RYRl mutations cause the upregulation of ITPRs transcripts.

\section{Changes in Intracellular $\mathrm{Ca}^{2+}$ Homeostasis in RYR1 Knocked Down Myotubes}

Using the human muscle cell line we assessed how down regulation of RyR1 by siRNA affects calcium homeostasis. Besides the resting $\left[\mathrm{Ca}^{2+}\right]$ and the size ionomycin sensitive $\mathrm{Ca}^{2+}$ stores, we measured several parameters, including the response (expressed as area under the curve, which more accurately reflects the total amount of $\mathrm{Ca}^{2+}$ released) of myotubes to $\mathrm{KCl}$-induced depolarization, to pharmacological activation of RyR1 with 4chloro-m-cresol and to ATP stimulation (which measures $\mathrm{Ca}^{2+}$ release via IP3R) in control cells, control cells treated with the IP3R inhibitor Xestospongin C and in RYR1 siRNA treated cells $( \pm$ Xestospongin $C)$. This approach allows us to evaluate if the decrease in $\mathrm{Ca}^{2+}$ released due to downregulation of RyR1 could be compensated by up-regulation of IP3Rmediated $\mathrm{Ca}^{2+}$ release. Fig. 7 shows that RyR 1 activation either directly by the addition of $600 \mu \mathrm{M} 4$-chloro-m-cresol or indirectly, by the addition of $60 \mathrm{mM} \mathrm{KCl}$ induces a large $\mathrm{Ca}^{2+}$ release that is independent of IP3Rs since the same amount of $\mathrm{Ca}^{2+}$ was released whether cells had been pre-treated or not with Xestospongin C. Downregulation of $R Y R 1$ by $50 \mathrm{nM}$ siRNA caused a 3 -fold decrease of $\mathrm{Ca}^{2+}$ release by $4-\mathrm{cmc}$ and $\mathrm{KCl}$ that was unaffected by Xestospongin C. Addition of $100 \mu \mathrm{M}$ ATP (i) caused the release of approximately $50 \%$ of the $\mathrm{Ca}^{2+}$ compared to the release obtained by RyR1 activation, (ii) was inhibited by Xestospongin 
$\mathrm{C}$ and importantly, (iii) was unaffected by down-regulation of RYRl. Downregulation of RyR1 affected neither the resting $\left[\mathrm{Ca}^{2+}\right]$ nor the total amount of ionomycin-induced $\mathrm{Ca}^{2+}$ release, indicating no significant effect on the size of the intracellular $\mathrm{Ca}^{2+}$ stores. These results indicate that upregulation of IP3R does not functionally compensate the decreased $\mathrm{Ca}^{2+}$-release due to the lower levels of RyR1 protein content. 


\section{Discussion}

RYRl-related disorders with mainly dominant inheritance and normal RyR1 protein expression have been extensively studied at the functional level, whereas the mechanisms underlying $R Y R$ l-related myopathies with recessive inheritance and RyR1 deficiency remain only partially understood. Functional studies of common dominant RYRI mutations associated with CCD indicate two principal mechanisms associated with disturbed function of the mutant RyR1 channel, namely presence of a 'leaky channels' associated with reduction of SR calcium stores (Lynch et al., 1999), or "uncoupled" channels with muscle weakness resulting from a reduced capacity of RyR1 to transport $\mathrm{Ca}^{2}$ (Avila et al., 2001). In the present study, we report that recessive $R Y R 1$ mutations associated with RyR1 deficiency are also responsible for E-C uncoupling by negatively affecting DHPR-RyR1 co-localization in skeletal muscle. Indeed, this kind of E-C uncoupling was initially reported in two animal models of RYRl-related disorders, the sporadic zebrafish relatively relaxed mutant with marked reduction of functional RyR1 protein (Hirata et al., 2007), and in Ryrl knockout (dyspedic) mice which do not express any ryanodine receptor 1 (Takeshima et al., 1994). In dyspedic myotubes cultured from Ryrl knockout mice there is no E-C coupling, whereas introduction of exogenous RyR1 restores E-C coupling and increases the density of the Ltype $\mathrm{Ca}^{2+}$ current towards normal (Nakai et al., 1996). The dependence of physiological E-C coupling on correct mechanical coupling is also indicated by ultrastructural studies demonstrating the importance of a tight alignment of RyR tetramers on the junctional face membrane and of DHPR molecules (a tetrad) on the opposing T-tubule membrane (Block et al., 1988).

Interestingly, depletion of RyR1 in vitro by siRNA in an immortalized human muscle cell line caused a decrease of $\mathrm{Ca}_{\mathrm{v}} 1.1$ content, suggesting that proper alignment between the two calcium channels is required for the stability of the complex. Diminishment of $\mathrm{Ca}_{\mathrm{v}} 1.1$ 
content has also been reported in dyspedic mouse skeletal muscle (Buck et al., 1997) and in one previous immunohistochemical study on core myopathies, in which a patient exhibiting virtual absence of RyR1 showed focal accumulation of DHPR within or around the cores (Herasse et al., 2007). The loss of DHPR/RyR1 co-localization strongly suggests a physical E-C uncoupling in patients with some recessive $R Y R l$ mutations. We suggest that the characteristic staining pattern of $\mathrm{Ca}_{\mathrm{v}} 1.1$ may be a useful immunohistochemical indicator to select patients for $R Y R l$ sequencing, currently still very costly and time consuming due to the large size of the gene.

Aside the down-regulation of $\mathrm{Ca}_{\mathrm{v}} 1.1$, we observed down-regulation of SERCA2 and alfa-actinin in RyR1 knocked-down myotubes. This is in contrast to the up-regulation of SERCA reported in dyspedic myotubes (Eltit et al., 2010; Eltit et al., 2011) and to the lack of changes in SERCA2 and alfa-actinin protein levels in the patient's biopsies. Opposing effects on SERCA2 expression have been reported in $\mathrm{C}_{2} \mathrm{C}_{12}$ cells transfected with two different RYR1 mutations. Vega et al. (Vega et al., 2011) reported that transfection with the RYRI Y523S MH-linked mutation caused an increase in SERCA2 expression whereas transfection of $\mathrm{C} 2 \mathrm{C} 12$ cells with the CCD-linked I4897T RYRI mutation caused its down-regulation. Furthermore they also reported that the expression of a particular mutant affects the degree of myotube differentiation, in that $\mathrm{C} 2 \mathrm{C} 12$ cells transfected with the RyR1 cDNA harbouring the I4897T mutation were similar to control myotubes in size and fusion index 8 days after differentiation, while cells transfected with the RyR1 cDNA harbouring the Y523S substitution were larger than control myotubes (Vega et al., 2011). We did not find any significant differences in size and in the expression of differentiation-related markers such as dystroglycan 1, troponin T1, myosin heavy chain and desmin (Galbiati et al., 1999; Trendelenburg et al., 2009) in RYR1siRNA transfected and control cells. Thus knocking down a protein in vitro does not mimic all aspects of what happens in vivo in muscles of 
patients harbouring recessive mutations causing RyR1 depletion and further experiments are required to understand the mechanisms involved in the reciprocal regulation of SR proteins.

In the present study we demonstrate that in human skeletal muscle under conditions of RyR1 deficiency, IP3R are up-regulated. In cultured mouse skeletal muscle cells IP3R are predominantly expressed around the nuclear envelope, are mainly associated with slow $\mathrm{Ca}^{2+}$ transients and appear to be involved in the regulation of gene expression (Jaimovich et al., 2000; Jaimovich and Carrasco, 2002). The IP3/IP3R-induced calcium signal plays little or no substantial role in skeletal muscle E-C coupling under physiological conditions (Posterino and Lamb, 1998) and as shown in the present study, up-regulation of IP3R in RyR1-deficient states does not compensate for the physical collapse of the E-C coupling machinery. Nevertheless, the IP3/IP3R pathway may be involved in slow calcium release leading to activation of expression of certain genes and the present study indicates the possible existence of a complex interplay RyR1 and IP3R signalling pathways.

In conclusion, our results demonstrate up-regulation of an alternative calcium regulating system via IP3R in recessive $R Y R 1$-related myopathies with RyR1 deficiency, and indicate the potential importance of the IP3R signalling cascade in the pathophysiology of these neuromuscular disorders. Future studies aimed at determining the role of the IP3R system in RyR1 deficient congenital myopathies and its correlation with disease progression could provide further insight into the pathogenesis of this condition. 


\section{Acknowledgement}

This work was supported by the Muscular Dystrophy Association awarded grant to FM (Grant number 174047); the Wellcome Trust Value in People awarded grant to HZ (Grant code FPEG). The SNF (grant $\mathrm{N}^{\circ} 3100$ 030_129785) to ST. KM and VM are supported by AFM and the $7^{\text {th }}$ FP EC network MYOAGE (Contract 223576). OR is supported by the Botnar Stiftung, The support of the MRC Neuromuscular Centre to the Biobank is gratefully acknowledged. FM is supported by the Great Ormond Street Hospital Children's Charity. We would like to thank Mr Darren Chambers for muscle biopsy processing in this study. In addition the authors would like to acknowledge the platform for culture and immortalization of the Myology Institute in Paris (France).

\section{Conflict of Interest}

The authors declare that they have no conflict of interest. 


\section{References}

Avila G, O'Brien JJ, Dirksen RT. 2001. Excitation--contraction uncoupling by a human central core disease mutation in the ryanodine receptor. Proc Natl Acad Sci U S A 98:4215-4220.

Block BA, Imagawa T, Campbell KP, Franzini-Armstrong C. 1988. Structural evidence for direct interaction between the molecular components of the transverse tubule/sarcoplasmic reticulum junction in skeletal muscle. J Cell Biol 107:25872600 .

Buck ED, Nguyen HT, Pessah IN, Allen PD. 1997. Dyspedic mouse skeletal muscle expresses major elements of the triadic junction but lacks detectable ryanodine receptor protein and function. J Biol Chem 272:7360-7367.

Clarke NF, Waddell LB, Cooper ST, Perry M, Smith RL, Kornberg AJ, Muntoni F, Lillis S, Straub V, Bushby K, Guglieri M, King MD, et al. 2010. Recessive mutations in RYR1 are a common cause of congenital fiber type disproportion. Hum Mutat 31:E1544-E1550.

Dirksen RT, Avila G. 2002. Altered ryanodine receptor function in central core disease: leaky or uncoupled $\mathrm{Ca}(2+)$ release channels? Trends Cardiovasc Med 12:189-197.

Dowling JJ, Lillis S, Amburgey K, Zhou H, Al-Sarraj S, Buk SJ, Wraige E, Chow G, Abbs S, Leber S, Lachlan K, Baralle D, et al. 2011. King-Denborough syndrome with and without mutations in the skeletal muscle ryanodine receptor (RYR1) gene. Neuromuscul Disord 21:420-427.

Ducreux S, Zorzato F, Muller C, Sewry C, Muntoni F, Quinlivan R, Restagno G, Girard T, Treves S. 2004. Effect of ryanodine receptor mutations on interleukin-6 release and intracellular calcium homeostasis in human myotubes from malignant hyperthermia-susceptible individuals and patients affected by central core disease. J Biol Chem 279:43838-43846.

Dulhunty AF, Pouliquin P. 2003. What we don't know about the structure of ryanodine receptor calcium release channels. Clin Exp Pharmacol Physiol 30:713-723.

Eltit JM, Li H, Ward CW, Molinski T, Pessah IN, Allen PD, Lopez JR. 2011. Orthograde dihydropyridine receptor signal regulates ryanodine receptor passive leak. Proc Natl Acad Sci U S A 108:7046-7051.

Eltit JM, Yang T, Li H, Molinski TF, Pessah IN, Allen PD, Lopez JR. 2010. RyR1-mediated $\mathrm{Ca} 2+$ leak and $\mathrm{Ca} 2+$ entry determine resting intracellular $\mathrm{Ca} 2+$ in skeletal myotubes. J Biol Chem 285:13781-13787.

Galbiati F, Volonté D, Engelman JA, Scherer PE, Linsanti MP. 1999. Targeted downregulation of caveolin-3 is sufficient to inhibit myotube formation in differentiating C2C12 myoblasts. J Biol Chem 274: 30315-30321. 
Herasse M, Parain K, Marty I, Monnier N, Kaindl AM, Leroy JP, Richard P, Lunardi J, Romero NB, Ferreiro A. 2007. Abnormal distribution of calcium-handling proteins: a novel distinctive marker in core myopathies. J Neuropathol Exp Neurol 66:57-65.

Hirata H, Watanabe T, Hatakeyama J, Sprague SM, Saint-Amant L, Nagashima A, Cui WW, Zhou W, Kuwada JY. 2007. Zebrafish relatively relaxed mutants have a ryanodine receptor defect, show slow swimming and provide a model of multiminicore disease. Development 134:2771-2781.

Jaimovich E, Carrasco MA. 2002. IP3 dependent Ca2+ signals in muscle cells are involved in regulation of gene expression. Biol Res 35:195-202.

Jaimovich E, Reyes R, Liberona JL, Powell JA. 2000. IP(3) receptors, IP(3) transients, and nucleus-associated $\mathrm{Ca}(2+)$ signals in cultured skeletal muscle. Am J Physiol Cell Physiol 278:C998-C1010.

Jungbluth H, Muller CR, Halliger-Keller B, Brockington M, Brown SC, Feng L, Chattopadhyay A, Mercuri E, Manzur AY, Ferreiro A, Laing NG, Davis MR, et al. 2002. Autosomal recessive inheritance of RYR1 mutations in a congenital myopathy with cores. Neurology 59:284-287.

Jungbluth H, Zhou H, Hartley L, Halliger-Keller B, Messina S, Longman C, Brockington M, Robb SA, Straub V, Voit T, Swash M, Ferreiro A, et al. 2005. Minicore myopathy with ophthalmoplegia caused by mutations in the ryanodine receptor type 1 gene. Neurology 65:1930-1935.

Jungbluth H, Zhou H, Sewry CA, Robb S, Treves S, Bitoun M, Guicheney P, Buj-Bello A, Bonnemann C, Muntoni F. 2007. Centronuclear myopathy due to a de novo dominant mutation in the skeletal muscle ryanodine receptor (RYR1) gene. Neuromuscul Disord. 17:338-345

Lynch PJ, Tong J, Lehane M, Mallet A, Giblin L, Heffron JJ, Vaughan P, Zafra G, MacLennan DH, McCarthy TV. 1999. A mutation in the transmembrane/luminal domain of the ryanodine receptor is associated with abnormal $\mathrm{Ca} 2+$ release channel function and severe central core disease. Proc Natl Acad Sci U S A 96:4164-4169.

Mamchaoui K, Trollet C, Bigot A, Negroni E, Chaouch S, Wolff A, Kandalla PK, Marie S, Di SJ, St Guily JL, Muntoni F, Kim J, et al. 2011. Immortalized pathological human myoblasts: towards a universal tool for the study of neuromuscular disorders. Skelet Muscle 1:34.

Manzur AY, Sewry CA, Ziprin J, Dubowitz V, Muntoni F. 1998. A severe clinical and pathological variant of central core disease with possible autosomal recessive inheritance. Neuromuscul Disord 8:467-473.

Monnier N, Procaccio V, Stieglitz P, Lunardi J. 1997. Malignant-hyperthermia susceptibility is associated with a mutation of the alpha 1-subunit of the human dihydropyridine-sensitive L-type voltage-dependent calcium-channel receptor in skeletal muscle. Am J Hum Genet 60:1316-1325. 
Nakai J, Dirksen RT, Nguyen HT, Pessah IN, Beam KG, Allen PD. 1996. Enhanced dihydropyridine receptor channel activity in the presence of ryanodine receptor. Nature 380:72-75.

Oddoux S, Brocard J, Schweitzer A, Szentesi P, Giannesini B, Brocard J, Faure J, PernetGallay K, Bendahan D, Lunardi J, Csernoch L, Marty I. 2009. Triadin deletion induces impaired skeletal muscle function. J Biol Chem 284:34918-34929.

Pan Z, Yang D, Nagaraj RY, Nosek TA, Nishi M, Takeshima H, Cheng H, Ma J. 2002. Dysfunction of store-operated calcium channel in muscle cells lacking mg29. Nat Cell Biol 4:379-383.

Pirone A, Schredelseker J, Tuluc P, Gravino E, Fortunato G, Flucher BE, Carsana A, Salvatore F, Grabner M. 2010. Identification and functional characterization of malignant hyperthermia mutation T1354S in the outer pore of the Cavalpha1Ssubunit. Am J Physiol Cell Physiol 299:C1345-C1354.

Posterino GS, Lamb GD. 1998. Investigation of the effect of inositol trisphosphate in skinned skeletal muscle fibres with functional excitation-contraction coupling. J Muscle Res Cell Motil 19:67-74.

Quane KA, Healy JM, Keating KE, Manning BM, Couch FJ, Palmucci LM, Doriguzzi C, Fagerlund TH, Berg K, Ording H. 1993. Mutations in the ryanodine receptor gene in central core disease and malignant hyperthermia. Nat Genet 5:51-55.

Ramachandran S, Serohijos AW, Xu L, Meissner G, Dokholyan NV. 2009. A structural model of the pore-forming region of the skeletal muscle ryanodine receptor (RyR1). PLoS Comput Biol 5:e1000367.

Takeshima H, Iino M, Takekura H, Nishi M, Kuno J, Minowa O, Takano H, Noda T. 1994. Excitation-contraction uncoupling and muscular degeneration in mice lacking functional skeletal muscle ryanodine-receptor gene. Nature 369:556-559.

Toppin PJ, Chandy TT, Ghanekar A, Kraeva N, Beattie WS, Riazi S. 2010. A report of fulminant malignant hyperthermia in a patient with a novel mutation of the CACNA1S gene. Can J Anaesth 57:689-693.

Trendelensburg AU, Meyer A, Rohner D, Boyle J, Hatakeyama S, Glass DJ. 2009.Myostatin reduced Akt/TORC1/p70S6K signaling, inhibiting myoblast differentiation and myotube size. Am J Physiol Cell Physiol 296: C1258-C1270.

Treves S, Jungbluth H, Muntoni F, Zorzato F. 2008. Congenital muscle disorders with cores: the ryanodine receptor calcium channel paradigm. Curr Opin Pharmacol 8:319326.

Treves S, Vukcevic M, Griesser J, Franzini-Armstrong C, Zhu MX, Zorzato F. 2010. Agonist-activated $\mathrm{Ca} 2+$ influx occurs at stable plasma membrane and endoplasmic reticulum junctions. J Cell Sci 123:4170-4181.

Van Petegem F. 2012. Ryanodine receptors: structure and function. J Biol Chem 287:3162431632. 
Vega AV, Ramos-Mondragon R, Calderon-Rivera A, Zarain-Herzberg A, Avila G. 2011. Calcitonin gene-related peptide restores disrupted excitation-contraction coupling in myotubes expressing central core disease mutations in RyR1. J Physiol 589:4649-4669.

Wilmshurst JM, Lillis S, Zhou H, Pillay K, Henderson H, Kress W, Muller CR, Ndondo A, Cloke V, Cullup T, Bertini E, Boennemann C, et al. 2010. RYR1 mutations are a common cause of congenital myopathies with central nuclei. Ann Neurol 68:717-726.

Zhou H, Jungbluth H, Sewry CA, Feng L, Bertini E, Bushby K, Straub V, Roper H, Rose MR, Brockington M, Kinali M, Manzur A, et al. 2007. Molecular mechanisms and phenotypic variation in RYR1-related congenital myopathies. Brain.

Zhou H, Lillis S, Loy RE, Ghassemi F, Rose MR, Norwood F, Mills K, Al-Sarraj S, Lane RJ, Feng L, Matthews E, Sewry CA, et al. 2010. Multi-minicore disease and atypical periodic paralysis associated with novel mutations in the skeletal muscle ryanodine receptor (RYR1) gene. Neuromuscul Disord 20:166-173.

Zhou H, Yamaguchi N, Xu L, Wang Y, Sewry C, Jungbluth H, Zorzato F, Bertini E, Muntoni F, Meissner G, Treves S. 2006. Characterization of recessive RYR1 mutations in core myopathies. Hum Mol Genet 15:2791-2803.

Zhu CH, Mouly V, Cooper RN, Mamchaoui K, Bigot A, Shay JW, Di Santo JP, ButlerBrowne GS, Wright WE. 2007. Cellular senescence in human myoblasts is overcome by human telomerase reverse transcriptase and cyclin-dependent kinase 4: consequences in aging muscle and therapeutic strategies for muscular dystrophies. Aging Cell 6:515-523. 
Figure 1: Protein expression of RyR1 and DHPR in muscle biopsy of patients with different $R Y R 1$ mutations. Double staining of RyR1 and DHPR, and NADH staining in muscle biopsies of patients with congenital myopathy and RYRl mutations. NADH staining was performed in non-serial sections from RyR1/DHPR double staining. Scale bar $=25 \mu \mathrm{m}$.

\section{Figure 2: Quantitative reverse transcriptional real-time PCR of $R Y R 1$ and} CACNA1S in skeletal muscle biopsies from patients carrying different $R Y R 1$ mutations.

The relative content of RYR1 and CACNA1S mRNA was assessed by real-time PCR using $\triangle \Delta \mathrm{Ct}$ method and using $D E S$ as muscle specific reference gene. The relative expression of RYRI and CACNA1S to DES in one of the control individuals was set as 1.0, and was used to calibrate the values of all other samples. Each symbol represents an individual and the bar indicates mean relative expression. ANOVA was used for the statistical analysis of the values in different groups, followed by the Bonferroni post statistics test. A) Relative expression of RYR1 transcript in muscle biopsies. B) Relative expression of CACNA1S transcript in muscle biopsies. * $\mathrm{P}<0.05,{ }^{* *} \mathrm{P}<0.01$.

Figure 3: RYR1, CACNA1S and DES mRNA expression in myotubes treated with $R Y R 1$ siRNA. The relative quantification of RYRI (A), CACNAIS (B) and DES (C) mRNA was performed by quantitative real-time PCR. The value was obtained from three independent transfection experiments of myotubes treated with RYRI siRNA at concentrations of $10 \mathrm{nM}, 30 \mathrm{nM}$ and $50 \mathrm{nM}$. The data is presented as Mean $\pm \mathrm{SEM}, \mathrm{N}=3$. ANOVA was used for the statistical analysis of the values in the RYRl siRNA treated myotubes to negative control siRNA, followed by Bonferroni post statistics test. The relative expression of target genes in control siRNA treated myotubes was set as 1.0, and was used to normalize the values in the RYR1 siRNA treated myotubes. * $\mathrm{P}<0.05,{ }^{*} \mathrm{P}<0.01$.

Figure 4: Down-regulation of RyR1 by RYR1 siRNA transfection does not affect myotube differentiation: Cells were transfected with $50 \mathrm{nM} R Y R 1$ siRNA, differentiated for 
5 days and then stained with $\beta$-tubulin and DAPI, the diameter of myotubes with $>3$ nuclei were measured and averagedconsidered. (A). Mean $( \pm \mathrm{SE})$ myotube diameter $(\mu \mathrm{m})$ of 30 transfected and 30 mock transfected myotubes. (B). Relative mRNA expression of differentiation-related markers; Dystroglycan 1 (DAG), Myosin heavy chain 1 (MYH1), Troponin $T 1$ (TNNT1) and Desmin (DES) normalized to GAPDH expression as internal control (N=6). (C). Immunofluorescentce of transfected (RYR1siRNA) or mock transfected (control) myotubes stained with anti- $\beta$ tubulin (green) and DAPI and observed with a Nikon A1R confocal microscope with a 40X NeoFluar objective (1.4 NA). Bar indicates $30 \mu \mathrm{m}$.

Figure 5: RyR1, DHPR and other SR protein in RYR1 siRNA treated myotubes and muscle biopsies from patients with RyR1 deficiency due to recessive $R Y R 1$ mutations

A) Representative western blots of RyR1, DHPR, IP3R-III, $\alpha$-actinin 2, SERCA 2, desmin and $\beta$-tubulin in human myotubes treated by $R Y R 1$ siRNA. B) Semi-quantification of proteins in RYRl siRNA treated myotubes. The expression of proteins was normalized to tubulin. Protein content in RYRl siRNA treated group was compared to the control group. C) Representative western blots of RyR1, DHPR, IP3R-III, $\alpha$-actinin 2, SERCA 2, and desmin in muscle biopsies from 2 patients (patient 2 and 5 in Table 1) with recessive RYR1

mutations. D) Semi-quantification of proteins in two patients, with RyR1 deficiency due to recessive $R Y R 1$ mutations, and three controls. The expression of proteins was normalized by desmin.

Figure 6: The expression of ITPR1, ITPR2 and ITPR3 mRNA in RYR1 siRNA treated myotubes and skeletal muscle biopsies from patients with different $R Y R 1$ mutations. A) The relative expression of ITPRs mRNA in cultured myotubes treated with siRNA was measured by quantitative reverse transcript real-time PCR. Data is presented as Mean \pm SEM. $\mathrm{N}=4$ samples per group. $* \mathrm{P}<0.05$. B) The relative expression of ITPRs mRNA measured by quantitative real-time PCR in skeletal muscle biopsies from controls $(\mathrm{N}=7)$, patients with 
dominant $R Y R 1$ mutations $(\mathrm{N}=5)$ and patients with complex recessive $R Y R 1$ mutations with RyR1 protein deficiency (N=6). GAPDH was used as general internal control gene. C) The relative expression of ITPRs mRNA measured by quantitative real-time PCR in skeletal muscle biopsies by using $D E S$ as muscle-specific internal control gene.

\section{Figure 7: Analysis of calcium regulation in a human muscle cell line after transfection}

with RYR1 siRNA. Cells were transfected with $50 \mathrm{nM}$ RYR1 siRNA or mock transfected as described in the Methods section and were either untreated or treated with $1 \mu \mathrm{M}$ Xestospongin C during the 40 minutes of fura-2 loading. Myotubes were stimulated with the indicated agonist in Krebs-Ringer containing no added $\mathrm{Ca}^{2+}$ plus $100 \mu \mathrm{M} \mathrm{La}^{3+}$ and the total amount of calcium released was calculated using Origin software by calculating the total transient, i.e. the area under the curve. Resting $\left[\mathrm{Ca}^{2+}\right]$ is presented as fluorescence ratio $(340 / 380 \mathrm{~nm})(\mathrm{au})$ before cell stimulation in Krebs-Ringer containing $2 \mathrm{mM} \mathrm{Ca}^{2+}$; the total amount of rapidly releasable $\mathrm{Ca}^{2+}$ present in the SR/ER stores was obtained by calculating the area under the curve after exposing cells to $1 \mu \mathrm{M}$ ionomycin in the Krebs-Ringer containing no added $\mathrm{Ca}^{2+}$ plus $0.5 \mathrm{mM}$ EGTA. For details see Methods section. All results are expressed as mean value ( \pm SEM) of the indicated number of cells. White bars mock transfected cells, grey bars cells transfected with RYRI siRNA. Statistical analysis was performed using Student's $t$-test. 
Figure 1

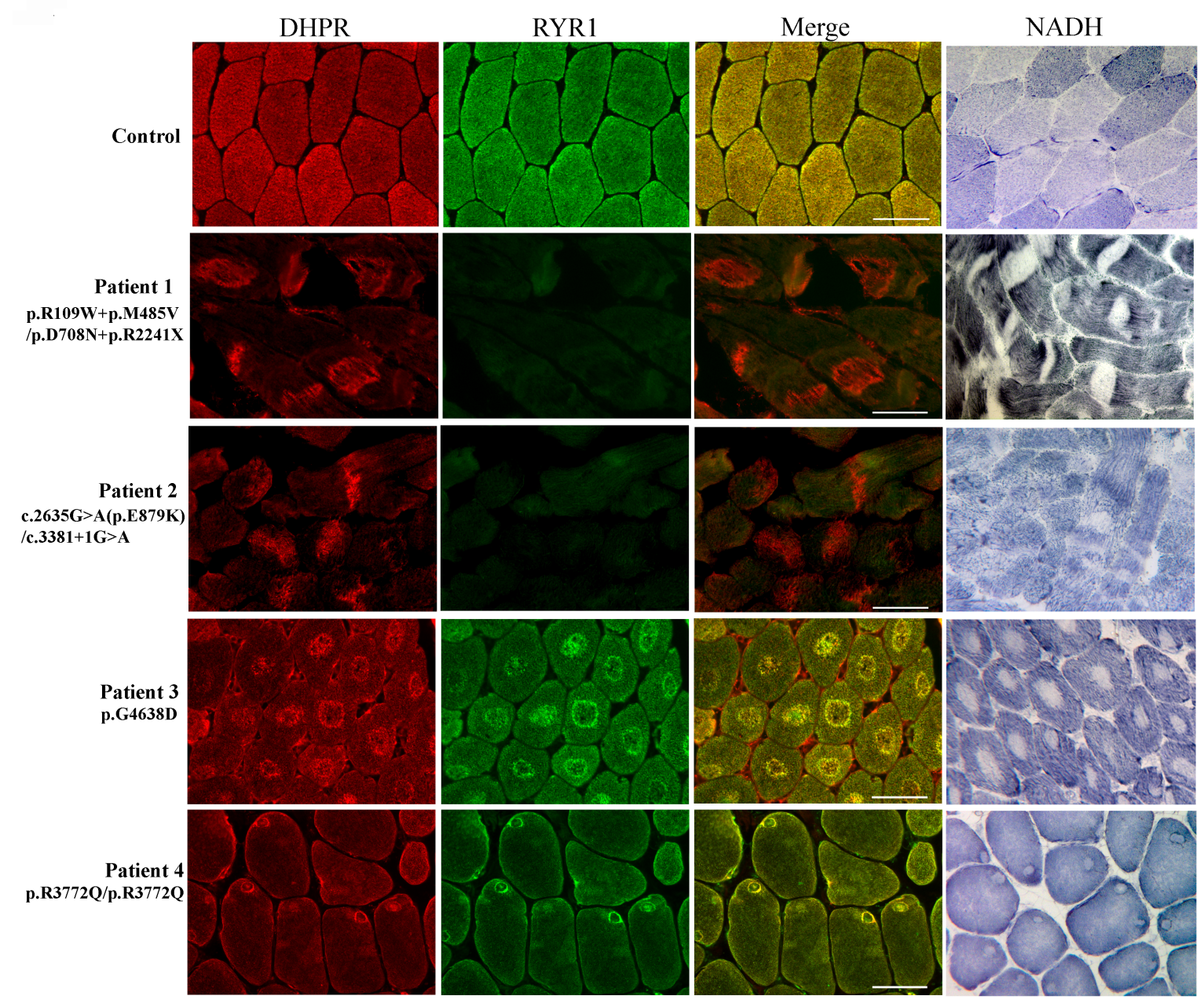

Figure 2

A

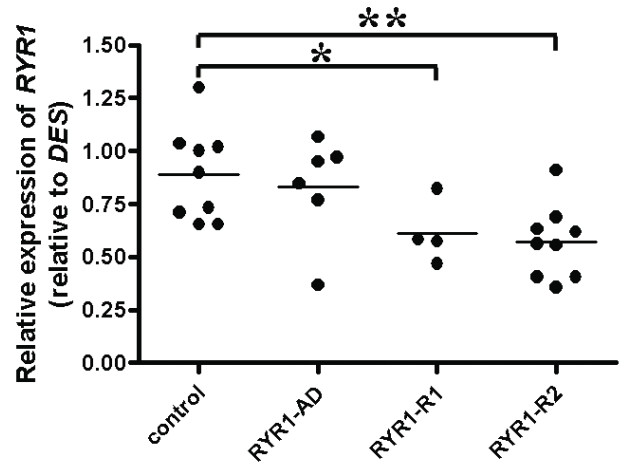

B

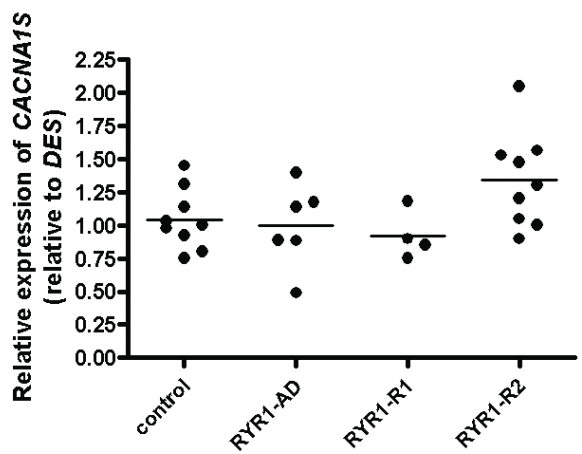


Figure 3

A

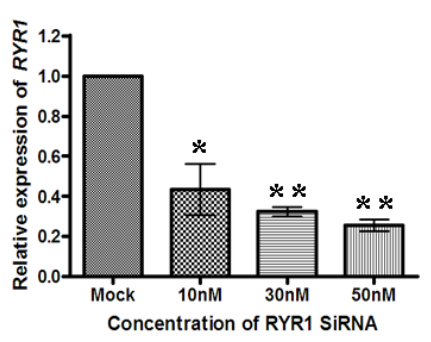

B

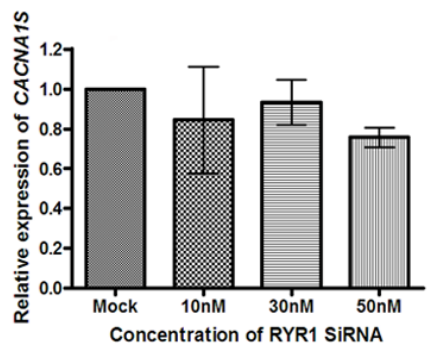

C

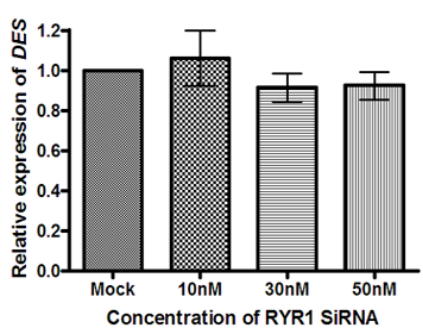

\section{Figure 4}
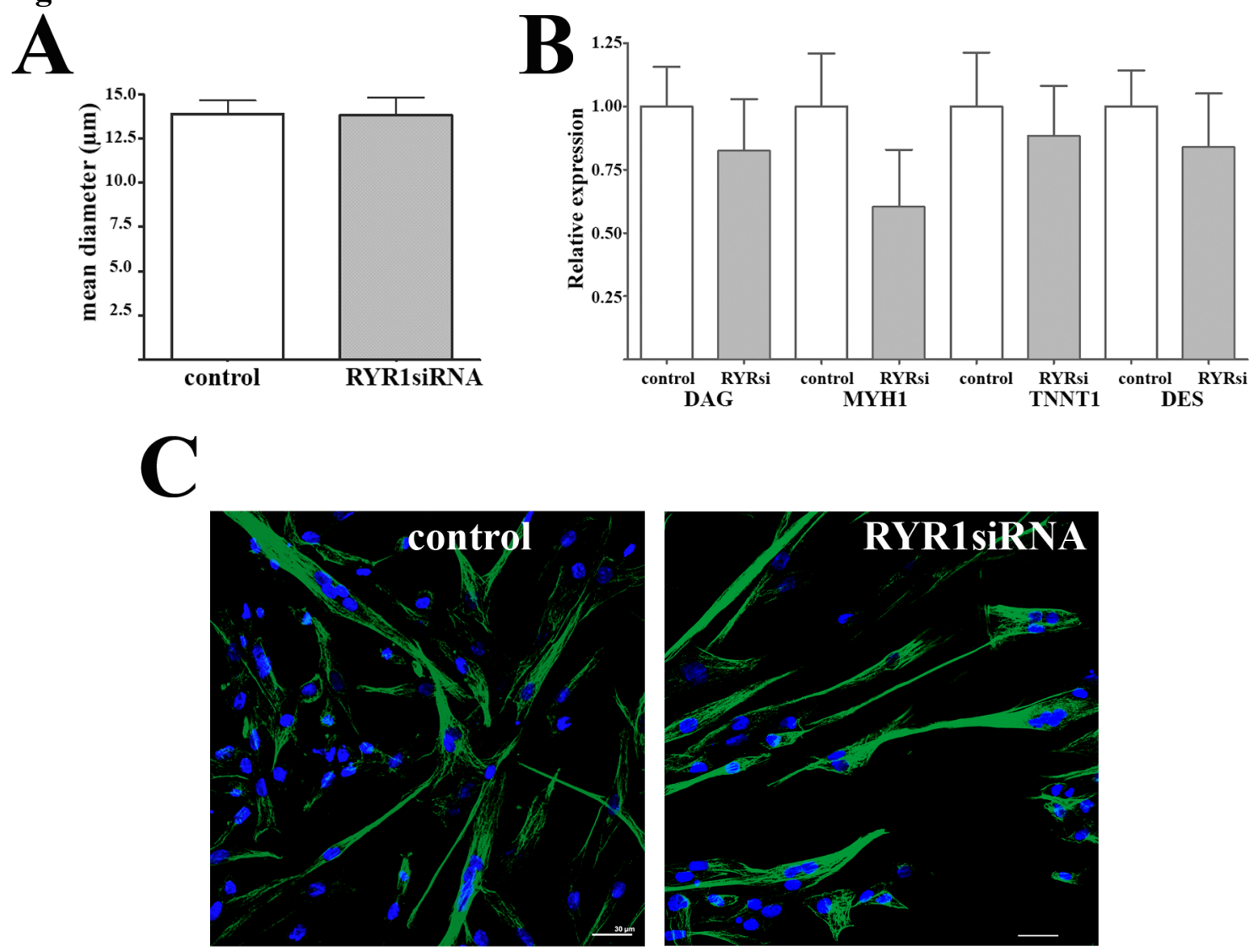
Figure 5

A

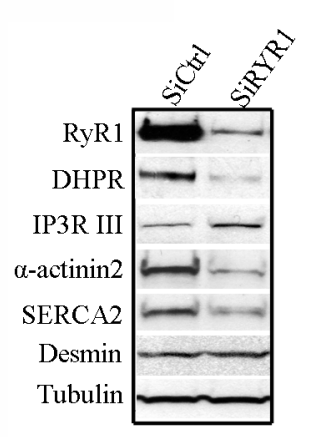

C

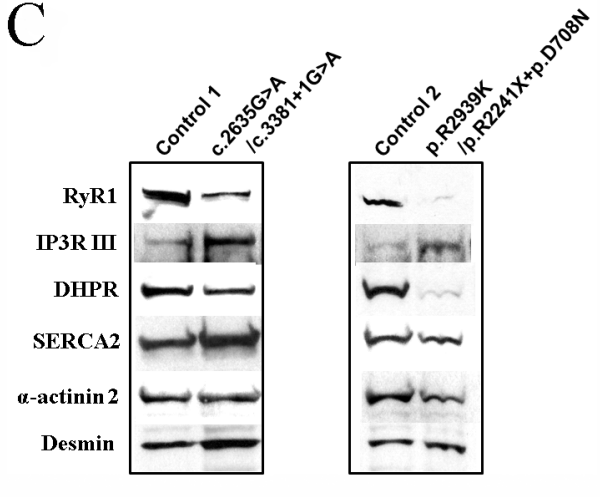

B

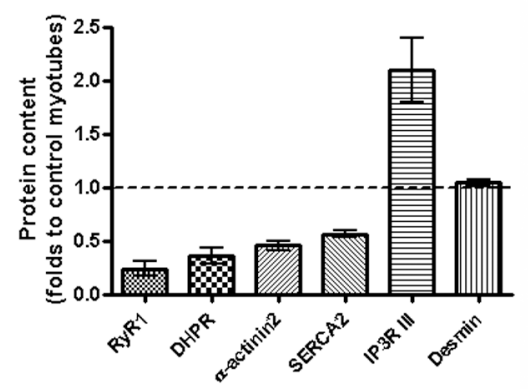

D $\square^{\text {Controls (n }=3)}$ שUp.R2939Kjp.R2241X+p.D708N

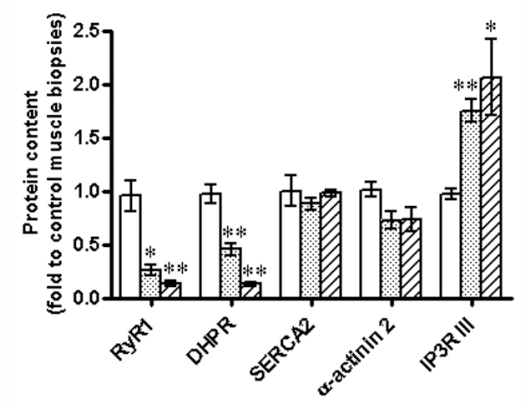

Figure 6 

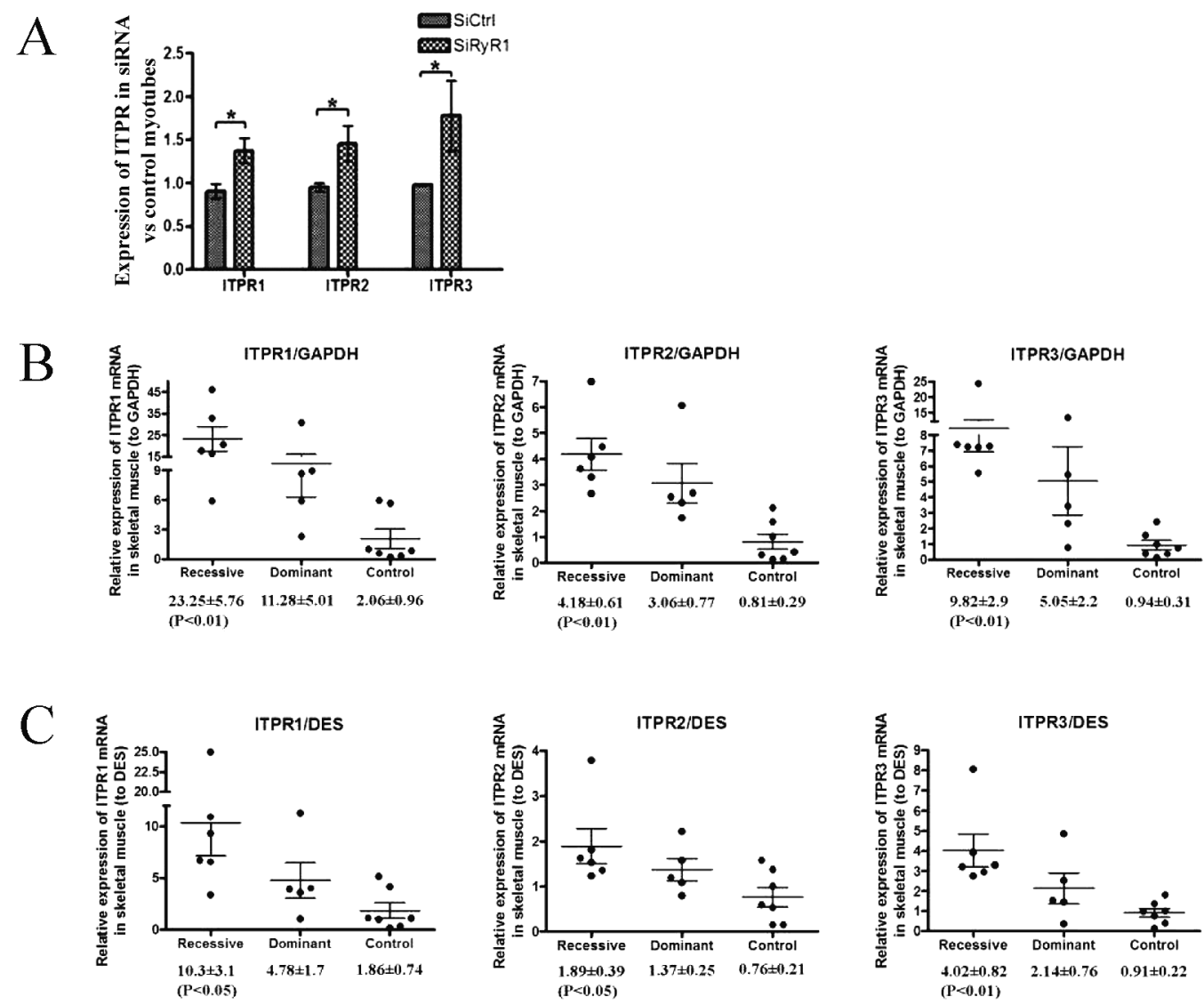
Figure 7
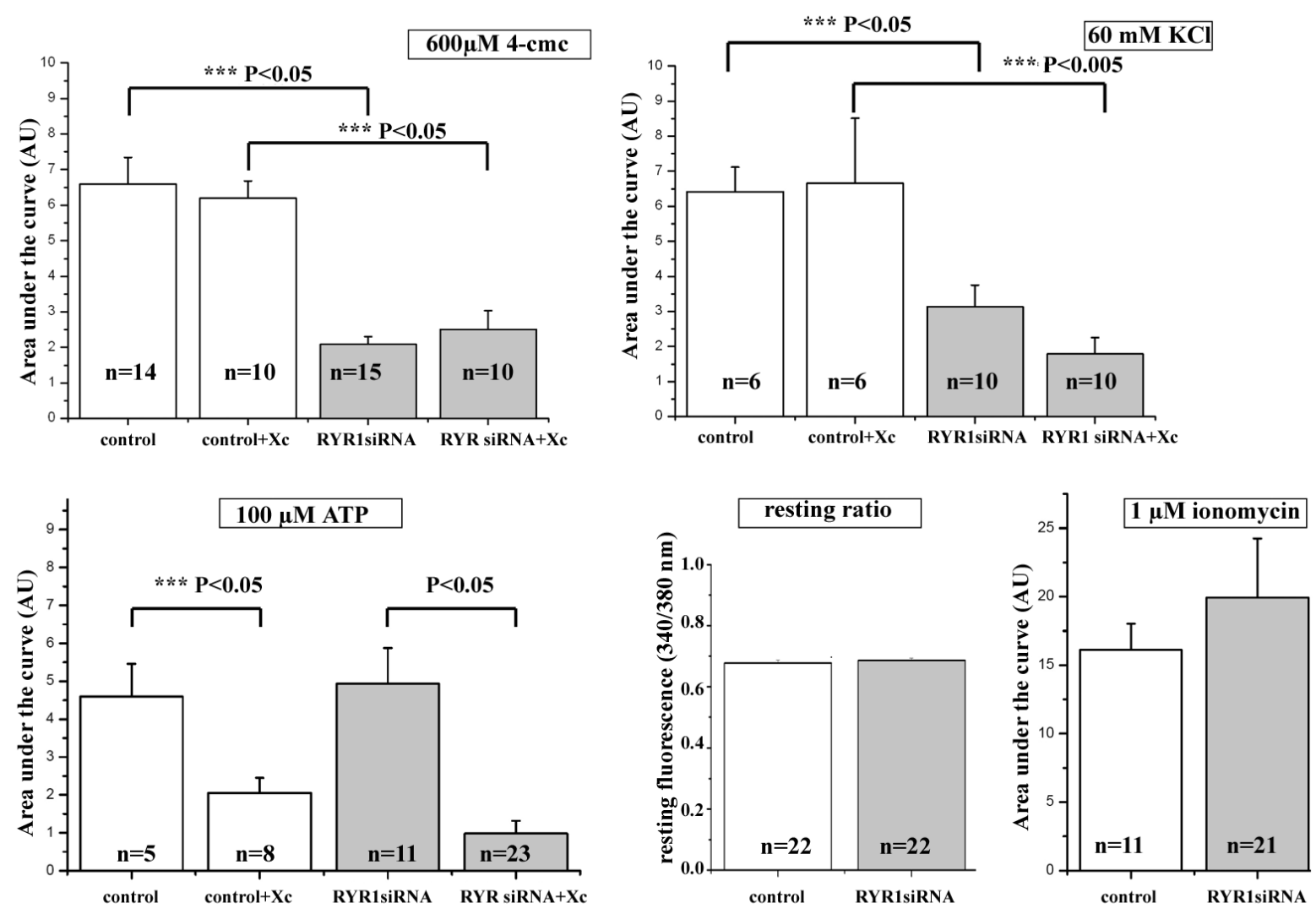